O AUTOR

Ismar de Oliveira Soares

Coordenador do Núcleo de Comunicação e Educação (NCE) ${ }^{2}$

do Departamento de Comunicações e Artes da ECA-USP.

Vice-Presidente (regional) do World Council for Media

Education (WCME).E-mail: ismar@usp.br

\title{
BIBLIOGRAFIA SOBRE COMUNICAÇÃO E EDUCAÇÃO ${ }^{1}$
}

COMUNICAÇÃO \& SOCIEDADE. São Bernardo, São Paulo: UMESP, n. 32, 2. sem. 1999. 280p.

Comunicação \& Sociedade tem divulgado a produção intelectual de pesquisadores e especialistas em comunicação, professores da Universidade Metodista e outras instituições. Este número da revista reúne um conjunto de artigos de interesse sobre o tema comunicação organizacional. Ao contrário do que ocorre com as empresas, onde a questão é trabalhada há mais tempo, vislumbrando novas possibilidades de integração entre atividades e redefinindo a práxis da comunicação nas organizações, só recentemente esta área vem sendo abordada com maior ênfase no campo acadêmico. Com o aprofundamento da pesquisa, o assunto passa a ganhar base teórica condizente com uma realidade social cada vez mais complexa.

BARBIERI, Marisa Ramos (coord.). Aulas de Ciências - Projeto LEC-PEC de ensino de ciências. Ribeirão Preto, São Paulo: Holos, 1999. 68p.

Esta é uma coletânea de trabalhos de professores de Ciências de escolas estaduais das cidades de Sertãozinho, Barrinha e Pontal (São Paulo) organizada pelo Laboratório de Ensino de Ciências - LEC, da Faculdade de Filosofia, Ciências e 
Letras da USP - Ribeirão Preto, e desenvolvida através de um projeto conjunto entre o LEC e o Programa de Educação Continuada, da Secretaria da Educação do Estado de São Paulo. O Projeto, desenvolvido entre os anos de 1997-98, teve como principal objetivo a construção de metodologias com as quais os professores pudessem investigar temas para ensinar Ciências, dando ênfase à transdisciplinaridade. Esta publicação reúne uma amostra dos trabalhos produzidos durante o projeto, incluindo temas como Astronomia, Evolução, Nutrição, Violência e Biodiversidade.

ELIZALDE, Luciano H. Los jóvenes y sus relaciones cotidianas con los medios.

Buenos Aires: Facultad de Ciencias de la Información/Universidad Austral, n.2, 1999. 128p. Colección Cuadernos Australes de Comunicación.

O objetivo deste trabalho é o de compreender quais são os fatores que constituem e influenciam a relação que os jovens estabelecem cotidianamente com os meios de comunicação. A investigação desenvolvida pelo autor valeu-se de uma metodologia de registro e análise das idéias, das ações dos jovens e dos conhecimentos que eles têm sobre os meios. O estudo procurou compreender mais profundamente como se dá o relacionamento dos jovens com as diferentes linguagens e tecnologias de comunicação, como se origina esta relação e que influências os meios exercem sobre eles na atual configuração da sociedade argentina.

\section{TEIJEIRO, Carlos Álvarez. Fundamentos teóricos del public journalism. Buenos}

Aires: Facultad de Ciencias de la Información/Universidad Austral, n. 4, 1999. 96p. Colección Cuadernos Australes de Comunicación.

Este trabalho contempla, de forma crítica, as complexas relações entre a dimensão política da comunicação pública e a dimensão comunicativa da política; colocando em discussão o papel dos meios de comunicação em relação à conformação dos sistemas políticos contemporâneos e à gestão dos espaços públicos. Ressaltam-se problemas que atravessam a própria participação dos meios na dimensão política, evidenciando o mal-estar democrático das sociedades contemporâneas. O autor expõe a filosofia política que inspira o public journalism, apresentando-o como o primeiro movimento a analisar os fundamentos do lugar institucional da profissão de informar.

NAKAZAWA, Keiji. Gen - pés descalços. São Paulo: Conrad Editora do Brasil, 1999. 284p.

Este livro é uma história autobiográfica. Seu autor, Keiji Nakazawa, tinha sete anos quando Hiroshima, sua cidade, foi destruída pela bomba atômica. Gen - pés descalços é um relato eletrizante e comovente, em forma de história em quadrinhos, que conta a história de um menino que cresce em uma família pacifista, durante a Segunda Guerra, e que enfrenta a devastação física e espiritual causada pelo homem. É uma mensagem de paz e humanidade que já ganhou versões para cinema, ópera e desenho animado. Gen e seu autor são aclamados por dois dos maiores artistas de quadrinhos da história: Art Spiegelman e Robert Crumb. 